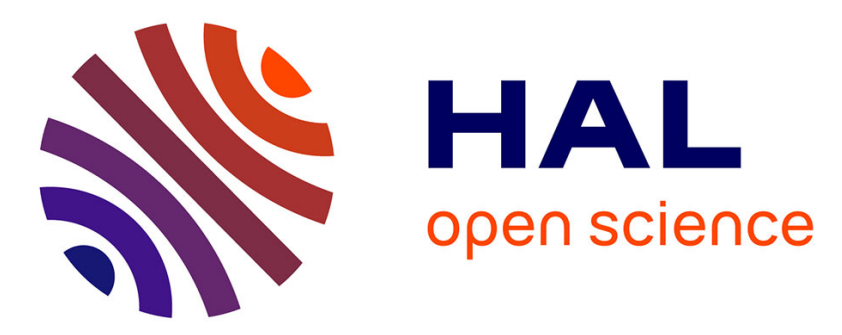

\title{
Agents Involved and Severity of Acute Ocular Exposure Reported at a Poison Control Center
}

\author{
G. Le Roux, Adrien Buisset, Stéphanie Leruez, Emmanuel Puskarczyk, \\ Philippe Gohier, Alexis Descatha
}

\section{- To cite this version:}

G. Le Roux, Adrien Buisset, Stéphanie Leruez, Emmanuel Puskarczyk, Philippe Gohier, et al.. Agents Involved and Severity of Acute Ocular Exposure Reported at a Poison Control Center. Ophthalmic Epidemiology, 2020, 27 (6), pp.468-476. 10.1080/09286586.2020.1773871 . hal-02861508

\section{HAL Id: hal-02861508 \\ https://univ-angers.hal.science/hal-02861508}

Submitted on 25 Jun 2020

HAL is a multi-disciplinary open access archive for the deposit and dissemination of scientific research documents, whether they are published or not. The documents may come from teaching and research institutions in France or abroad, or from public or private research centers.
L'archive ouverte pluridisciplinaire HAL, est destinée au dépôt et à la diffusion de documents scientifiques de niveau recherche, publiés ou non, émanant des établissements d'enseignement et de recherche français ou étrangers, des laboratoires publics ou privés. 


\section{Agents involved and severity of acute ocular exposure reported at a poison control center}

Gaël Le Roux ${ }^{1}$, Adrien Buisset ${ }^{2}$, Stéphanie Leruez ${ }^{3}$, Emmanuel Puskarczyk ${ }^{4}$, Philippe Gohier $^{2}$, Alexis Descatha ${ }^{1,5}$

Running head: Ocular exposure in poison control center

Corresponding author: Gaël Le Roux

Grand Ouest Poison Control and Toxicovigilance Center, Angers University Hospital, 4 rue Larrey, 49933 Angers Cedex 9

Phone: +33241355354

Email: GaLeRoux@chu-angers.fr

Financial support: None

Conflicts of interest: None of the authors have any proprietary interests or conflicts of interest related to this submission

Previous reviewing: This work has not been reviewed previously

Keywords: chemical eye burns, poison center, occupational injuries, childhood accident, detergent, household products

Word count: 4227 words

\footnotetext{
${ }^{1}$ Grand Ouest Poison Control and Toxicovigilance Center, University Hospital, Angers, France

${ }^{2}$ Ophthalmology Department, University Hospital, Angers, France

${ }^{3}$ Centre Ophtalmologique Saint Joseph, Clinique Saint Joseph, 49800 Trelazé

${ }^{4}$ Est Poison Control and Toxicovigilance Center, French national database of products and compositions, University Hospital, Nancy, France

${ }^{5}$ Univ Angers, CHU Angers, Univ Rennes, Inserm, EHESP, Irset (Institut de recherche en santé, environnement et travail) - UMR_S1085, F-49000 Angers, France
} 
Purpose. Knowing the use categories of the products involved and on the circumstances of exposure, the aim was to identify severity factors useful in the initial management of patients in case of acute ocular exposure.

Methods. A retrospective study over a one-year period, on patients having used a poison center for eye exposure to a chemical substance.

\section{Results.}

In one year, 1582 patients were concerned. The sex ratio $(\mathrm{M} / \mathrm{F})$ was 0.8 . The mean age was $28.5 \pm 20.3$ years. Among children, those under 4 years represented the most significant age category $(n=277 ; 50.1 \%)$. Exposure to chemicals were mild $(n=1342,84.8 \%)$. Adults over 65 years appeared to be more likely to have more severe ocular damage (OR: $4.75 ;$ [2.26; 9.98]). Unintentional exposures were the most frequent $(n=1548 ; 97.8 \%)$. Ocular exposure primarily occurred at home $(n=937 ; 59.2 \%)$ then at work $(n=396 ; 25 \%)$, but with a higher risk of severe injury (OR: 2.93 [2.16; 3.97]). Cleaning products accounted for $31.2 \%$ of exposure cases $(n=457)$. Exposure to disinfectants appears to be a risk factor in more severe injuries (OR: 1.48 [1.002; 2.19] $\mathrm{p}=0.0472)$. $\mathrm{PH}$ and severity of injuries were not statistically associated.

Conclusions. Our study showed the very wide variety in products involved in ocular exposures. Taking into account severity found, specific attention should be made by clinician on some of them like extreme ages, working exposure, and products like disinfectant and not only acid vs. base. 


\section{Introduction}

The exposure of the ocular surface to toxic products, particularly irritants, is potentially a risk factor of serious ophthalmological complications, such as corneal scarring, corneal opacity, or permanent vision lost $[1,2]$.

Despite this fact, there are only a few large studies available from emergency services and without systematic study of recording, such as a register of cases seen in emergency rooms, it is difficult to have a clear idea of the epidemiology of ocular chemical exposure. In the 2016 annual report by the American Association of Poison Centers (AAPC), ocular exposure represented $4.22 \%$ of cases reported at poison control centers [3]. In the United States, chemical burns represent $1.5 \%$ of ophthalmological emergencies and 7 to $18 \%$ of eye trauma cases [4]. In France, in 2013, the ocular route represented $6.0 \%$ of exposure routes registered by the network of French poison control centers [5, 6]. Regarding the characteristics of the materials involved, very little data is available. In that respect, in a 1993 study of 102 Indian patients, acids and bases were responsible for $83.5 \%$ of cases [7], although in a recent American study of 143,985 patients published in 2016, acids and bases were only found in $11.8 \%$ of cases [8]. In fact, other categories of products exist which are rarely taken into account, but which are frequently associated in formulations (phenols, peroxides, surfactants, etc.).

The aim of this study is to describe one year assistance provided by a poison control center, a recommended structure for the management of chemical eye burns by detailing the categories of use of the products, and to identify risk factors for serious injury following exposure of the ocular surface to toxic products.

\section{Materials and methods}


A descriptive retrospective study on the poison control center (PCC) managing the regions of North-West France was carried out over a period of one year, between May 1, 2016 and April 31, 2017. The PCC fulfills the role of providing urgent toxicological advice to poisoned patients in the North-Western quarter of France: the regions of Normandie, Bretagne, CentreVal de Loire and Pays de la Loire (12 million inhabitants, 20\% of the French population).

\subsection{Source of data}

The included cases have been defined as patients having used the PCC during the period for exposure to a chemical substance via ocular route. The data collected and analyzed came from the BNCI (base national des cas d'intoxication, the French national database of intoxication cases) from the SICAP (system d'information commun des CAP, the French poison control center system for shared information). This database is approved by the CNIL (Commission nationale Informatique et Libertés, the French Data Protection Authority) (authorization $\left.\mathrm{n}^{\circ} 747735\right)$. Personal data regarding the patients was anonymized prior to the data analysis. For each case, the information analyzed was the date and time of exposure, the age and sex of the person exposed, the agent of exposure and its composition, the symptoms, the circumstances, the place of exposure, the severity and the progression of each case.

Cases of exposure to a foreign body or physical agents (radiation) were removed from the study.

The agents involved were derived from the BNPC (base nationale des produits et compositions, the French national database of products and compositions) who compile combined or unmixed substances and classify them in usage category. In the interest of simplification and clarity, the usage categories have been designated by letters. The key is provided in Table 1.

The severity is assessed according to the Poisoning Severity Score (PSS): low, PSS1 (minor symptoms such as irritation, conjunctival hyperemia, lacrimation, conjunctival damage, minor 
palpebral edema); moderate, PSS2 (pronounced or prolonged signs, such as intense irritation, punctate keratitis); high, PSS3 (severe symptoms such as significant ulceration or even corneal perforation, corneal scarring) [9].

\subsection{Statistical analysis}

The data has been presented in a descriptive manner, as well as the variables associated with the severity such as a PSS score of two or more with simple logistic regression models for crude odds ratios (OR). Statistical Analysis Software was used (Version 9.4, SAS Institute Inc., Cary, NC, USA).

\section{Results:}

In the period between May 2016 and April 2017, Grand Ouest PCC provided toxicological advice for 32,497 exposed patients, including all routes of exposure. Among them, 1582 patients $(4.9 \%)$ had been exposed to a chemical product exclusively through the ocular route.

\subsection{Description of the sample group \\ 3.1.1. Groups by age and sex}

The sex ratio $(\mathrm{M} / \mathrm{F})$ was 0.8 (704 men, 878 women). The average age was $28.5 \pm 20.3$ years; the median age was 27 years. The distribution of age and sex is shown in Table 2.

Among children, those between 0 and 4 years represented the most significant age category $(277 ; 50.1 \%$ of those between 0 and 18 years). The sex ratio $(\mathrm{M} / \mathrm{F})$ in this age category is 1.3 . The exposure agents most frequently found in the cases of children between 0 and 4 years correspond to products in category A $(123 / 277$; 44.4\%). Products for cleaning textiles represented $48.7 \%$ of cases in this usage category. In particular, the average age of those exposed to a hydrosoluble liquid laundry detergent capsule was $7.4 \pm 10.7$ years, compared to $25.3 \pm 17.2$ years for other types of liquid detergent $(p<0.001)$. Next to laundry detergents, 
surface degreasers were involved in $9.4 \%$ (26/277 cases) of exposure. Other usage categories found in cases of exposure of young children were cosmetic products (category D; 44/277; $15.8 \%)$ such as nail care products (15 cases) or perfume (19 cases), pharmaceutical products (category C; 38/277; 13.7\%), mainly antiseptics or disinfectants for cutaneous use (23 cases). In adults $(962 ; 60.8 \%)$, products from category A were still the most commonly involved (277/962; 28.8\%), mainly surface degreasers (56 cases) and dishwashing detergents (43 cases), as well as disinfectant products (category B; 123/962; 12.8\%), mainly bleach (46 cases), disinfectants for milking and farming equipment (34 cases) and surface disinfectants (29 cases).

Those over 65 years old represented $5.3 \%$ of patients ( 85 cases). The products found largely belonged to the category of human medicinal products $(16 / 85 ; 18.8 \%)$, mainly being medicinal products for dermatological use. Household bleach was also frequently involved $(11 / 85 ; 14.1 \%)$.

\subsubsection{Places of exposure}

The distribution of places of exposure is shown in Table 2. Ocular exposure primarily took place in the home $(937 ; 59.2 \%)$. Category A products were the most frequently involved in cases of exposure $(295 / 937 ; 31.5 \%)$, mainly via textile care products $(109 / 937 ; 11.6 \%)$ and cleaning products $(78 / 937 ; 8.3 \%)$, followed by medicinal products belonging to class $\mathrm{C}$ $(142 / 937 ; 15.2 \%)$.

Ocular exposures that took place in the workplace accounted for $25 \%$ of cases (396 cases). These mainly happened in a factory or a warehouse $(61 / 396 ; 15.5 \%)$ or on a farm $(54 / 396$; 13.7\%). Again, class A products were the most frequently involved (94/396; 23.7\%), mainly in the form of cleaning products (45 cases). Another two categories were each responsible for more than $15 \%$ of workplace exposure cases: category G $(64 / 396 ; 16.2 \%$, mainly food 
preparation surface disinfectants) and category B (62/396; 15.7\% of cases, mainly caused by disinfectants for milking and farming equipment).

Educational institutions were the place of exposure in $5.8 \%$ of cases (91 cases). Other locations where exposure took place (care facilities, enclosed public places, community day care or leisure centers, and prison facilities) account for less than 50 cases each.

\subsubsection{Circumstances of exposure}

The distribution of circumstances of exposure is shown in Table 2. In $97.8 \%$ of cases (1548 cases), ocular exposures registered in the study were unintentionally caused. Occupational injuries were the most numerous $(515 / 1548 ; 33.3 \%)$. The distribution of agents responsible for occupational exposures can be superimposed over the distribution for workplace exposures. Thus, categories A $(141 / 515 ; 27.4 \%$ of professional cases $)$, B $(184 / 515 ; 16.3 \%)$ and $\mathrm{G}(72 / 515 ; 14.0 \%)$ are the most frequent.

Cases of non-occupational exposure (1033 cases) were mainly daily life injuries in the broad sense $(331 / 1033 ; 32.0 \%$ of unintentional cases $)$, failing to perceive risk $(276 / 1548 ; 17.8 \%)$, a DIY, household or gardening injuries $(306 / 1548 ; 26.7 \%)$, or a therapeutic error $(118 / 1548$; $11.4 \%)$

When the exposure was unintentional, it took place with category A products (309/1033; $29.9 \%$ of unintentional cases), category $\mathrm{C}$ products $(151 / 1033 ; 14.6 \%)$ such as medicinal products for cutaneous use, and category D products $(117 / 1033 ; 11.3 \%)$ such as insect repellents and essential oils.

Products from categories $\mathrm{E}$ and $\mathrm{H}$ in exposure cases linked to DIY $(69 / 306,22.5 \%$ of cases linked to DIY) mainly involved anti-moss and lichen products (20 cases), glues (mostly cyanoacrylates, 19 cases) and paints and stains (mainly xyloprotectors, 18 cases).

Lastly, therapeutic error occurred in $33.0 \%$ of cases $(39 / 118)$ with erroneous application of chlorhexidine to the eye. In children, exposure to category $\mathrm{C}$ was twice as likely by 
therapeutic error as by failing to perceive risk ( 15 vs. $32 ; 19.0 \%$ vs. $40.5 \%$ of exposure to this category of agents in minors)

Exposure was intentional in 34 cases (2.1\%) and mainly involved the substance being thrown into another individual's eyes (20 cases). Among these cases, 9 corresponded to the use of tear gas.

\subsection{Exposure agents}

In total, 1151 different agents were involved in ocular exposures. They are divided as follows: mixtures (1093 agents; 95.0\%), individual substances (44 agents; 4.0\%), plants and animals (14 agents; $1.3 \%$ ). The principal order of usage categories is described in Table 2. Products of category A alone accounted for 31.2\% of exposure cases (457 cases). Among them, cleaning products were represented mainly by surface cleaners/degreasers $(94 / 452 ; 20.8 \%$ ) and household or professional dishwashing detergents $(53 / 457 ; 11.6 \%)$. Textile care products $(114 / 457 ; 24.9 \%)$ were mostly represented by liquid laundry detergents $(102 ; 89.7 \%$ of cases of exposure to any type of laundry detergents).

Category B products were present in $10.2 \%$ of exposure cases (161 cases). They represented by three subcategories: household bleach $(67 / 161 ; 41.6 \%)$, surface disinfectants $(39 / 161$; $24.2 \%)$ and disinfectants for milking and farming equipment $(36 / 161 ; 22.3 \%)$.

Category $\mathrm{C}$ products were involved in 156 exposure cases $(9.7 \%)$, principally antiseptics and disinfectants $(62 / 156 ; 39.7 \%)$, ophthalmological medicinal products $(16 / 156 ; 10.3 \%)$ and ear medicinal products $(9 / 156 ; 5.8 \%)$. Products from categories D and F represented 210 cases (13.3\%). The most common were: lice repellent products $(37 / 210 ; 17.6 \%)$; nail care products $(36 / 210 ; 17.1 \%)$; perfumes and colognes $(25 / 210 ; 11.9 \%)$; essential oils $(21 / 210 ; 10.0 \%$, mainly peppermint essential oil).

Products belonging to category E as well as category I represented $9.8 \%$ of cases (155 cases). These were mainly glues and associated products $(43 / 155 ; 27.7 \%)$, paints, varnishes and 
stains $(39 / 155 ; 25.2 \%)$, as well as anti-moss and lichen products $(38 / 155 ; 24.5 \%)$. Animals and plants were involved in 37 exposure cases (2.3\%). One single case involved exposure to toad venom toxins. In the case of plants, $80.6 \%$ of cases involved the genus Euphorbia. The other usage categories are described in Table 3.

Making the traditional distinction of acids vs. bases, the patients were distributed in the following way: $11.7 \%(185 / 1582)$ exposed to an acid, $24.7 \%(393 / 1582)$ exposed to a base, $12.3 \%(195 / 1582)$ a neutral product and lastly $16.9 \%(268 / 1582)$ to a product to which the concept of $\mathrm{pH}$ does not apply (solvent etc.).

\subsection{Severity of exposures}

Ocular exposure to chemical products mostly caused low intensity symptoms according to the PSS: 19 cases (1.2\%) of no severity (PSS 0), 1323 cases (83.6\%) of low severity (PSS 1), 226 cases $(14.3 \%)$ of moderate severity (PSS 2$)$, and 11 cases $(0.7 \%)$ of high severity (PSS 3 ) were identified. In 3 cases, the severity was not determinable due to a lack of sufficient clinical information in the patient's file.

There was a statistically significant association between the age and the severity of ocular damage, as shown in Table 2. Adults, particularly those over 65 years appeared to be more likely to present with more severe ocular damage (OR: $4.75 ; \mathrm{p}<0.0001)$.

Occupational exposure was associated with a higher risk of severe ocular injury (OR: 2.34; $\mathrm{p}<0.0001)$, as well as workplace exposure (OR: 2.93; $\mathrm{p}<0.0001)$.

Comparing ocular exposure to category A agents, exposure to disinfectants, broadly speaking, appeared to be a risk factor in more severe injuries (OR: 1.48; $\mathrm{p}=0.0472)$. Cases of moderate to high severity (PSS 2/3) represented $22.9 \%$ of cases $(55 / 295)$ of exposure in all circumstances taken together, 30.0\% of cases of occupational exposure (39/169 cases). Disinfectants for milking or farming were involved in $71.4 \%$ of cases of exposure $(15 / 21$ 
cases) In the case of household bleach, 8 out of 11 cases of PSS $2 / 3$ severity $(17.7 \%$ of household bleach cases) involved a "concentrated" product (above 9.6\% active chlorine).

Whatever the circumstances, exposure to medicinal products, hygiene and personal care products was significantly less severe than exposure to category A agents (OR: $0.43 ; \mathrm{p}=$ $0.0001)$.

Cases ranked as a severity of PSS $2 / 3$ accounted for $21.2 \%$ of exposures $(33 / 155)$ to agents in the E and I categories. In the category of glues and sealing products, the proportion of PSS $2 / 3$ cases reaches $25.5 \%$ (11/46 cases) and $28.9 \%$ for products for removing moss from facades. In almost all cases (34 cases out of 38), these products had a quaternary ammonium base in varying concentrations.

No significant connection between $\mathrm{pH}$ and the severity of injuries has been revealed. Among the most severe injuries (PSS 3), we found a clear prevalence of men at $75 \%$. Among the 12 people exposed, 2 were children under 5 years old who were both exposed to liquid detergent pods, although one did not have the eye rinsed immediately. The others were exposed to disinfectants and products for industrial use. Three of the people exposed presented a limbic ischemia that was discovered in an ophthalmological appointment, two needed an amniotic membrane graft and four presented sequela in the cornea.

\section{Discussion}

This study made it possible to describe one year of assistance provided by a multiregional structure and to identify the severity risk factors of exposing the ocular surface to toxic products. Our study is also the first to take interest in the usage categories of the products involved in ocular exposures beyond the traditional dichotomy of acid vs. base, which does not fully reflect the diversity of agents. This analysis is made possible by the organized categorization of mixtures, the confidential compositions of which are available to poison centers. 
Our study showed the very wide variety in products involved in ocular exposures. This included more than one thousand products over one year of collecting data. Many of them met the definition of the European Biocidal Products Regulation, such as disinfectants (class B) preservatives (class G) or pest control products (class H). In a retrospective study of domestic ocular damage published in 2001 focusing on patients admitted to injuries and emergency, the products involved were spread across the following categories: alkalines ( $26.5 \%$ of patients), cleaning products, organic solvents, physical hygiene products, products for contact lenses and disinfectants [10]. Alkaline products were also involved in almost a quarter of exposures listed in our study, which is twice as high as for acids, as has already been shown by a British study led in 1987 [11]. We did not find any connection between the severity of the injuries and the $\mathrm{pH}$ of agents, which may encourage ophthalmologists and emergency doctors to look past this traditional paradigm. The category of disinfectants that appears to be the greatest cause of ocular damage, according to our results, is a good illustration of this: it contains both alkaline products and oxidants (chlorine-based agents, aldehydes, quaternary ammonium, etc.).

Furthermore, it is reasonable to think that as a result of dilutions and mixtures, the $\mathrm{pH}$ indicated in the composition of mixtures or on the safety data sheets provided to poison centers, and that in the solution which comes into contact with the ocular surface, will be different. Therefore, the severity of the injuries depends not only on the concentration of the product, but also the quantity and duration of exposure [12]. This means that knowledge of the $\mathrm{pH}$ is not a relevant piece of information for the immediate treatment of patients or the evaluation of prognosis and does not replace an exhaustive description of the patient' symptoms and, above all, the circumstances of exposure.

Therefore, thanks to this study, we have shown that splashes on the ocular surface in professional environments and, subsequently, in the workplace are frequent and associated 
with more severe ocular injuries. This is what was found by epidemiological studies in various countries, as well as more frequent exposure among adults in the employed population. On the other hand, contrary to what was found in the literature, we found a majority of men only in cases of considerable severity (PSS 3) $[8,13]$. In a recent Spanish study, chemical burns represented $12.7 \%$ of ocular damage at the workplace and $11.9 \%$ of keratoconjunctivitis cases [14]. Under these professional circumstances, we observed that products for cleaning, maintenance, scouring and descaling are more frequent in a professional environment. This is fully consistent with the results from Quesada et al. [14], which found that the service and construction sectors were the most affected $(62.1 \%$ and $20.9 \%$ of cases, respectively). This is in accordance with the fact that products for an almost exclusively professional usage are also causes of average or severe damage: 1 case in 5 for the materials and products for using and treating construction materials (glues and solvents, moss and lichen removal), $22.5 \%$ of cases for surface disinfectants (22.5\% of PSS 2 cases), even almost three quarters (71.4\%) of cases of exposure to disinfectants for milking equipment and also the involvement of a concentrated product in $72.7 \%$ of cases of average exposure to household bleach.

Workers are usually subject to safety policies based on training about the risk of chemicals, establishing a standardized protocol for treating burns and even wearing personal protective equipment. It has already been shown that this type of equipment remains underused and its use must be promoted more strongly [15].

Children from 0 to 4 years old represented only half of cases of exposure among children under 18 years old. It is the exploratory behavior of children who are becoming more and more mobile that is given as the cause for the frequency of exposures. Although young children understand the distinction between good and bad behavior, they have no capacity to understand the consequences [16]. Therefore, it is the lack of risk perception that was the 
main case of ocular exposure in this age group. The prevalence of young boys is customary in cases of poisoning and is not specific to ocular exposures [3, 17]. The causes of exposure most frequently encountered by young children from 0 to 4 years old corresponded to products found at home (fabric cleaners, home maintenance products, cosmetic and hygiene products). For several years, there has been a real concern regarding the severity of ocular exposures to water-soluble laundry detergent pods, which is confirmed by a number of studies on the subject [18-20]. The bright colors and rounded and smooth appearance of the detergent pods are especially attractive. In addition, in our study, these causes represented almost half of exposures to cleaning products.

In our study, we observed that in the case of ocular exposures to medications, children were, in particular, victims of error in treatments, in that they received dangerous products as eye drops. These medical exposures perfectly illustrate the difficulty posed by pharmaceutical packaging that is too similar. In the same size and shape, with small labels that are hard to read, it can be difficult to distinguish one bottle from another. Over 7 years, a study of an Australian poison center made it possible to identify around 1,300 cases where drops of a medication that is not intended for use in the eyes was unintentionally administered [21]. Chlorhexidine, which we found the most often in our study, was one of the ten most frequently found products in the Australian study [21]. There are specific recommendations available for this type of administration error, such as to read packaging carefully, store ophthalmological medications separately and throw away products at the end of treatments $[21]$.

In more general terms, as shown by a case-control study in Great Britain [22], failing to put medications and household products away immediately after use in a locked cabinet and out of reach increases the risk of poisoning among children aged 0 to 4 years old. The authors 
believe that effective prevention on the subject would make it possible to significantly reduce these exposures among children [22].

The main limitations of this study are caused by its retrospective nature, on the one hand, and the fact that patients were contacted only by phone, on the other hand. There is also missing data, especially on points that are not essential to the patient's medical treatment. A prospective study on ocular damage in a professional environment must be conducted to identify the exact determining factors exposures, as well as more specific identification of risk factors.

\section{Conflicts of interest}

The authors have no conflicts of interest to declare.

\section{References}

[1] Wagoner MD. Chemical injuries of the eye: current concepts in pathophysiology and therapy. Surv Ophthalmol 1997;41:275-313. https://doi.org/10.1016/s00396257(96)00007-0.

[2] Eslani M, Baradaran-Rafii A, Movahedan A, Djalilian AR. The ocular surface $\begin{array}{lllll}\text { chemical } & \text { burns. } & \text { J } & \text { Ophthalmol }\end{array}$ https://doi.org/10.1155/2014/196827.

[3] Gummin DD, Mowry JB, Spyker DA, Brooks DE, Osterthaler KM, Banner W. 2017 Annual Report of the American Association of Poison Control Centers' National Poison Data System (NPDS): 35th Annual Report. Clin Toxicol 2018;56:1213-415. https://doi.org/10.1080/15563650.2018.1533727.

[4] Gicquel J-J, Dua H. Brûlures cornéennes. EMC - Ophtalmol 2011;8:1-12. https://doi.org/10.1016/s0246-0343(11)55721-1.

[5] Schrage N, Burgher F, Blomet J, Bodson L, Gérard M, Hall AH, et al. Chemical ocular 
burns: New understanding and treatments. Chem Ocul Burn New Underst Treat 2011:1-122. https://doi.org/10.1007/978-3-642-14550-6.

[6] Sinno-Tellier S, Daoudi J, Manel J. Epidémiologie en France: étude des cas d'exposition enregistrés par les centres antipoison français en 2013. In: Collectif, Baud F, Garnier R, editors. Toxicol. Clin., Paris: Lavoisier; 2017.

[7] Saini JS, Sharma A. Ocular chemical burns--clinical and demographic profile. Burns 1993;19:67-9. https://doi.org/10.1016/0305-4179(93)90104-g.

[8] Haring RS, Sheffield ID, Channa R, Canner JK, Schneider EB. Epidemiologic trends of chemical ocular burns in the United States. JAMA Ophthalmol 2016;134:1119-24. https://doi.org/10.1001/jamaophthalmol.2016.2645.

[9] Persson HE, Sjöberg GK, Haines JA, De Garbino JP. Poisoning severity score. Grading of acute poisoning. J Toxicol - Clin Toxicol 1998;36:205-13. https://doi.org/10.3109/15563659809028940.

[10] Berry M, Jeffreys D. Ocular injuries from household chemicals: Early signs as predictors of recovery. Vitr Mol Toxicol J Basic Appl Res 2001;14:5-13. https://doi.org/10.1089/109793301316882504.

[11] Ramponi DR. Chemical burns of the eye. Adv Emerg Nurs J 2017;39:193-8. https://doi.org/10.1097/TME.0000000000000152.

[12] Merle H, Gérard M, Schrage N. Brûlures oculaires. J Fr Ophtalmol 2008;31:723-34. https://doi.org/10.1016/S0181-5512(08)74391-2.

[13] Macdonald ECA, Cauchi PA, Azuara-Blanco A, Foot B. Surveillance of severe chemical corneal injuries in the UK. $\mathrm{Br} \mathrm{J}$ Ophthalmol 2009;93:1177-80. https://doi.org/10.1136/bjo.2008.154831.

[14] Quesada JMA, Lloves JM, Delgado DV. Ocular chemical burns in the workplace: Epidemiological characteristics. $\quad$ Burns $2019: 1-7$. 
https://doi.org/10.1016/j.burns.2019.11.007.

[15] Zakrzewski H, Chung H, Sanders E, Hanson C, Ford B. Evaluation of occupational ocular trauma: are we doing enough to promote eye safety in the workplace? Can J Ophthalmol 2017;52:338-42. https://doi.org/10.1016/j.jcjo.2016.11.034.

[16] Lee VR, Connolly M, Calello DP. Pediatric poisoning by ingestion: Developmental overview and synopsis of national trends. Pediatr Ann 2017;46:e443-8. https://doi.org/10.3928/19382359-20171121-01.

[17] Matsa E, Shi J, Wheeler KK, McCarthy T, McGregor M Lou, Leonard JC. Trends in us emergency department visits for pediatric acute ocular injury. JAMA Ophthalmol 2018;136:895-903. https://doi.org/10.1001/jamaophthalmol.2018.2062.

[18] Day R, Bradberry SM, Thomas SHL, Vale JA. Liquid laundry detergent capsules (PODS): a review of their composition and mechanisms of toxicity, and of the circumstances, routes, features, and management of exposure. Clin Toxicol 2019;57:1053-63. https://doi.org/10.1080/15563650.2019.1618466.

[19] Claudet I, Honorat R, Casasoprana A, Grouteau E, Franchitto N. Expositions des enfants aux lessives capsules, écodoses ou pods: Plus toxiques que les lessives traditionnelles? $\quad$ Arch Pediatr 2014;21:601-7. https://doi.org/10.1016/j.arcped.2014.03.020.

[20] Settimi L, Giordano F, Lauria L, Celentano A, Sesana F, Davanzo F. Surveillance of paediatric exposures to liquid laundry detergent pods in Italy. Inj Prev 2018;24:5-11. https://doi.org/10.1136/injuryprev-2016-042263.

[21] Brown JA. Medicinal mishaps: Incorrectly dropped in the eye. Aust Prescr 2013;36:56-56. https://doi.org/10.18773/austprescr.2013.026.

[22] Kendrick D, Majsak-Newman G, Benford P, Coupland C, Timblin C, Hayes M, et al. Poison prevention practices and medically attended poisoning in young children: 
Multicentre case-control study. Inj Prev 2017;23:93-101. https://doi.org/10.1136/injuryprev-2015-041828. 
Table 1. Main order of usage categories and corresponding code.

\begin{tabular}{|c|c|}
\hline Usage categories (main order) & Code \\
\hline Products for cleaning, maintenance, scouring and descaling & $\mathrm{A}$ \\
\hline Disinfectants (excluding medical equipment) & $\mathrm{B}$ \\
\hline Pharmaceutical products & $\mathrm{C}$ \\
\hline Cosmetics, personal hygiene products & $\mathrm{D}$ \\
\hline Materials and products for construction & $\mathrm{E}$ \\
\hline Personal care products & $\mathrm{F}$ \\
\hline Food contact products & G \\
\hline Phytopharmaceutical products & $\mathrm{H}$ \\
\hline Products for treating construction materials & I \\
\hline Fuels, flammables, solvents, lubricants & $\mathrm{J}$ \\
\hline Sport and leisure products & $\mathrm{K}$ \\
\hline Food and diet products & $\mathrm{L}$ \\
\hline Stimulants (excluding drugs and medications) & M \\
\hline Medical materials, accessories & $\mathrm{N}$ \\
\hline Non-food additives & $\mathrm{O}$ \\
\hline Weapon/self-defense item & $\mathrm{P}$ \\
\hline School and office supplies & Q \\
\hline Air conditioning, cooling and heating products & $\mathrm{R}$ \\
\hline Reagents, laboratory dyes, developing products & $\mathrm{S}$ \\
\hline Cell/accumulator/battery electrolyte & $\mathrm{T}$ \\
\hline Fire prevention products (extinguisher) & $\mathrm{U}$ \\
\hline Printing and copying products & $\mathrm{V}$ \\
\hline Water treatment products (excluding pools) & $\mathrm{W}$ \\
\hline Products for animals (e.g. litter) & $\mathrm{X}$ \\
\hline
\end{tabular}


Table 2. Description of the sample group, circumstances and usage categories of products involved in the ocular exposures in total, and according to severity.

\begin{tabular}{|c|c|c|c|c|c|c|c|}
\hline & \multicolumn{2}{|c|}{ PSS 0/1 } & \multicolumn{2}{|c|}{ PSS 2/3 } & \multirow[t]{2}{*}{ Total } & \multirow[t]{2}{*}{ OR [95\%CI] } & \multirow[t]{2}{*}{$p$} \\
\hline & $\mathrm{N}$ & $\%$ & $\mathrm{~N}$ & $\%$ & & & \\
\hline \multicolumn{8}{|l|}{ Age } \\
\hline $0-4$ years old & 255 & 92.39 & 21 & 7.61 & 276 & $1.36[0.68 ; 2.73]$ & 0.3901 \\
\hline $5-18$ years old & 231 & 94.29 & 14 & 5.71 & 245 & Reference & N/A \\
\hline $18-65$ years old & 778 & 80.96 & 183 & 19.04 & 961 & $3.88[2.21 ; 6.81]$ & $<0.0001$ \\
\hline Over 65 years old & 66 & 77.65 & 19 & 22.35 & 85 & $4.75[2.26 ; 9.98]$ & $<0.0001$ \\
\hline \multicolumn{8}{|l|}{ Usage categories } \\
\hline Categories K, P, Q, R, T, U & 56 & 96.55 & 2 & 3.45 & 58 & $0.18[0.04 ; 0.75]$ & 0.0182 \\
\hline Category A & 379 & 83.3 & 76 & 16.7 & 455 & Reference & N/A \\
\hline Categories B, G, W & 185 & 77.08 & 55 & 22.92 & 240 & $1.48[1.00 ; 2.19]$ & 0.0472 \\
\hline Categories C, D, F, L, M, N & 396 & 92.09 & 34 & 7.91 & 430 & $0.43[0.28 ; 0.66]$ & 0.0001 \\
\hline Categories E, I, O, S & 135 & 77.14 & 40 & 22.86 & 175 & $1.48[0.96 ; 2.27]$ & 0.0754 \\
\hline Categories H, X & 42 & 79.25 & 11 & 20.75 & 53 & $1.31[0.64 ; 2.65]$ & 0.4598 \\
\hline Categories J, V & 45 & 90 & 5 & 10 & 50 & $0.55[0.21 ; 1.44]$ & 0.2262 \\
\hline \multicolumn{8}{|l|}{ Sex } \\
\hline Female & 738 & 84.25 & 138 & 15.75 & 876 & Reference & N/A \\
\hline Male & 604 & 85.92 & 99 & 14.08 & 703 & $0.88[0.66 ; 1.16]$ & 0.3558 \\
\hline \multicolumn{8}{|l|}{ Place of exposure } \\
\hline Home & 834 & 89.1 & 102 & 10.9 & 936 & Reference & N/A \\
\hline Educational institute & 84 & 92.31 & 7 & 7.69 & 91 & $0.68[0.31 ; 1.51]$ & 0.3461 \\
\hline Hospital stay, care, accommodation & 38 & 80.85 & 9 & 19.15 & 47 & $1.94[0.91 ; 4.12]$ & 0.0863 \\
\hline Work & 290 & 73.6 & 104 & 26.4 & 394 & $2.93[2.16 ; 3.97]$ & $<0.0001$ \\
\hline Other location & 89 & 86.41 & 14 & 13.59 & 103 & $1.29[0.71 ; 2.34]$ & 0.4109 \\
\hline \multicolumn{8}{|l|}{ Circumstances } \\
\hline Everyday life & 260 & 88.14 & 35 & 11.86 & 295 & Reference & $\mathrm{N} / \mathrm{A}$ \\
\hline DIY, housework, gardening & 265 & 86.6 & 41 & 13.4 & 306 & $1.15[0.71 ; 1.86]$ & 0.5718 \\
\hline Error in the perception of risk & 252 & 91.3 & 24 & 8.7 & 276 & $0.71[0.41 ; 1.22]$ & 0.2155 \\
\hline Work & 390 & 76.02 & 123 & 23.98 & 513 & $2.34[1.56 ; 3.52]$ & $<0.0001$ \\
\hline Other & 175 & 92.59 & 14 & 7.41 & 189 & $0.59[0.31 ; 1.14]$ & 0.116 \\
\hline
\end{tabular}

A, Products for cleaning, maintenance, scouring and descaling; B, Disinfectants (excluding medical equipment);

C, Pharmaceutical products; D, Cosmetics, personal hygiene products; E, Materials and products for construction; F, Personal care products; G, Food contact products; H, Phytopharmaceutical products; I, Products for treating construction materials; J, Fuels, flammables, solvents, lubricants; K, Sport and leisure products; L, Food and diet products; M, Stimulants (excluding drugs and medications); N, Medical materials, accessories; O, Non-food additives; P, Weapon/self-defense item; Q, School and office supplies; R, Air conditioning, cooling and heating products; S, Reagents, laboratory dyes, developing products; T, Cell/accumulator/battery electrolyte; U, Fire prevention products (extinguisher); V, Printing and copying products; W, Water treatment products 
(excluding pools); X, Products for animals (e.g. litter). PSS, Poisoning Severity Score; OR, odds ratio; 95\%CI, 95\% Confidence Interval; DIY, do it yourself. 
Table 3. Organized order of the usage of products involved in the ocular exposures.

\begin{tabular}{|c|c|c|c|c|c|c|c|}
\hline & \multirow{2}{*}{ Order of usage } & \multicolumn{2}{|c|}{ PSS 0/1 } & \multicolumn{2}{|c|}{ PSS 2/3 } & \multicolumn{2}{|c|}{ Total } \\
\hline & & $\mathrm{N}$ & $\% \mathrm{a}^{\mathrm{a}}$ & $\mathrm{N}$ & $\%^{\mathrm{a}}$ & $\mathrm{N}$ & $\% \mathrm{~b}$ \\
\hline \multirow[t]{11}{*}{ A } & $\begin{array}{l}\text { Products for cleaning, maintenance, scouring and } \\
\text { descaling }\end{array}$ & 379 & 82.9 & 76 & 16.6 & 457 & 28.9 \\
\hline & Cleaning & 128 & 81.0 & 29 & 18.4 & 158 & 10.0 \\
\hline & Product for cleaning fabrics & 94 & 82.5 & 20 & 17.5 & 114 & 7.2 \\
\hline & Corrosive agent & 52 & 80.0 & 13 & 20.0 & 65 & 4.1 \\
\hline & Deodorizer/odorizer & 36 & 97.3 & 1 & 2.7 & 37 & 2.3 \\
\hline & Descaling agent & 28 & 82.4 & 5 & 14.7 & 34 & 2.1 \\
\hline & Vehicle maintenance product & 15 & 83.3 & 3 & 16.7 & 18 & 1.1 \\
\hline & Product for septic tank/pipes & 13 & 81.3 & 3 & 18.8 & 16 & 1.0 \\
\hline & Product for pool maintenance & 10 & 83.3 & 2 & 16.7 & 12 & 0.8 \\
\hline & Products for treating leathers and skins & 2 & 100.0 & & & 2 & 0.1 \\
\hline & Polishing/waxing product & 1 & 100.0 & & & 1 & 0.1 \\
\hline \multirow[t]{8}{*}{ B } & Disinfectants (excluding medical equipment) & 124 & 77.0 & 37 & $\mathbf{2 3 . 0}$ & 161 & 10.2 \\
\hline & Household bleach & 56 & 83.6 & 11 & 16.4 & 67 & 4.2 \\
\hline & Floor, wall, surface disinfectant & 32 & 82.1 & 7 & 17.9 & 39 & 2.5 \\
\hline & Disinfectant for milking and livestock farming equipment & 21 & 58.3 & 15 & 41.7 & 36 & 2.3 \\
\hline & Air disinfectant & 5 & 83.3 & 1 & 16.7 & 6 & 0.4 \\
\hline & Sanitary disinfectant (WC, bathroom) & 6 & 100.0 & & & 6 & 0.4 \\
\hline & Disinfectant for babies' bottles/dishes & 3 & 75.0 & 1 & 25.0 & 4 & 0.3 \\
\hline & Disinfectant for products for domestic animals & & & 1 & 100.0 & 1 & 0.1 \\
\hline \multirow[t]{4}{*}{$\mathbf{C}$} & Pharmaceutical products & 156 & 91.2 & 14 & 8.2 & 171 & 10.8 \\
\hline & Human medications & 139 & 90.3 & 14 & 9.1 & 154 & 9.7 \\
\hline & Veterinary medications & 14 & 100.0 & 0 & 0.0 & 14 & 0.9 \\
\hline & Phytotherapy & 2 & 100.0 & 0 & 0.0 & 2 & 0.1 \\
\hline \multirow[t]{14}{*}{ D } & Cosmetics, personal hygiene products & 118 & 95.9 & 5 & 4.1 & 123 & 7.8 \\
\hline & Nail care/varnish & 37 & 100.0 & & 0.0 & 37 & 2.3 \\
\hline & Perfume/eau de toilette/cologne & 25 & 100.0 & & 0.0 & 25 & 1.6 \\
\hline & Skin cleanser & 18 & 94.7 & 1 & 5.3 & 19 & 1.2 \\
\hline & Hair product & 12 & 85.7 & 2 & 14.3 & 14 & 0.9 \\
\hline & Deodorant/antiperspirant & 6 & 100.0 & & 0.0 & 6 & 0.4 \\
\hline & Bath and shower product & 5 & 100.0 & & 0.0 & 5 & 0.3 \\
\hline & Sun screen & 5 & 100.0 & & 0.0 & 5 & 0.3 \\
\hline & Skincare & 2 & 50.0 & 2 & 50.0 & 4 & 0.3 \\
\hline & Shaving product & 2 & 100.0 & & & 2 & 0.1 \\
\hline & Dental and oral hygiene & 2 & 100.0 & & & 2 & 0.1 \\
\hline & Face and/or body mask/exfoliation/peel & 2 & 100.0 & & & 2 & 0.1 \\
\hline & Make-up product & 1 & 100.0 & & & 1 & 0.1 \\
\hline & Cosmetic product for babies & 1 & 100.0 & & & 1 & 0.1 \\
\hline \multirow[t]{5}{*}{$\mathbf{E}$} & Materials and products for construction & 87 & 81.3 & 20 & 18.7 & 107 & 6.8 \\
\hline & Glue/adhesive/sealant and associated products & 32 & 74.4 & 11 & 25.6 & 43 & 2.7 \\
\hline & Paint/varnish/enamel/wood stain and associated products & 36 & 92.3 & 3 & 7.7 & 39 & 2.5 \\
\hline & Materials (including construction) & 14 & 70.0 & 6 & 30.0 & 20 & 1.3 \\
\hline & Rubber and plastic and associated products & 5 & 100.0 & & & 5 & 0.3 \\
\hline $\mathbf{F}$ & Personal care products & 77 & 88.5 & 10 & 11.5 & 87 & 5.5 \\
\hline
\end{tabular}


Insect repellent for humans applied to skin

Essential oil (personal care)

Hand sanitizer

Hygiene products for glasses/contact lenses

Cryotherapy and heat therapy

Massage cream/gel/oil (excluding medication)

ENT and eye hygiene without medicine

Dental hygiene equipment

\section{G Food contact products}

Disinfectant for food preparation surfaces (excluding dishes)

Cleaner for food preparation surfaces (excluding dishes)

\section{H Phytopharmaceutical products}

Pesticides for plants

Pesticides for animals

Surface repellent (excluding human/animal skin)

Fertilizer/soil enhancement

Additive for phytosanitary products

Tar/sealing putty

I Products for treating construction materials

Moss/lichen removal/fungicidal wash in masonry for construction materials

Anti-rust/rust removal product

Product for protecting/treating masonry for construction materials (wall, terrace, roof)

Soldering and brazing product

Oxidant

\section{J Fuels, flammables, solvents, lubricants}

Solvent

Fuel for combustion engine

Lubricant/unmolding agent

Heating and lamp fuel

K Sport and leisure products

Toy/gadget

Creative/decorative leisure product

L Food and diet products

Food/drink

Food supplement

Food additive

M Stimulants (excluding drugs and medications)

Electric cigarette

Tobacco

Aphrodisiacs (poppers)

N Medical materials, accessories

Medical disinfectant/sterilizing material

Medical care equipment

O Non-food additives

Additive for rubber and plastic

Non-food preservative

Perfuming preparation

\begin{tabular}{|c|c|c|c|c|c|}
\hline \multicolumn{2}{|c|}{ PSS 0/1 } & \multicolumn{2}{|c|}{ PSS 2/3 } & \multicolumn{2}{|c|}{ Total } \\
\hline 20 & 95.2 & 1 & 4.8 & 21 & 1.3 \\
\hline 25 & 92.6 & 2 & 7.4 & 27 & 1.7 \\
\hline 16 & 88.9 & 2 & 11.1 & 18 & 1.1 \\
\hline 6 & 66.7 & 3 & 33.3 & 9 & 0.6 \\
\hline 4 & 100.0 & & & 4 & 0.3 \\
\hline 4 & 100.0 & & & 4 & 0.3 \\
\hline \multirow[t]{2}{*}{2} & 66.7 & 1 & 33.3 & 3 & 0.2 \\
\hline & & 1 & 100.0 & 1 & 0.1 \\
\hline 59 & 78.7 & 16 & 21.3 & 75 & 4.7 \\
\hline 35 & 81.4 & 8 & 18.6 & 43 & 2.7 \\
\hline 24 & 77.4 & 7 & 22.6 & 31 & 2.0 \\
\hline 42 & 82.4 & 9 & 17.6 & 51 & 3.2 \\
\hline 21 & 75.0 & 7 & 25.0 & 28 & 1.8 \\
\hline 13 & 92.9 & 1 & 7.1 & 14 & 0.9 \\
\hline 4 & 100.0 & & & 4 & 0.3 \\
\hline \multirow[t]{2}{*}{3} & 100.0 & & & 3 & 0.2 \\
\hline & & 1 & 100.0 & 1 & 0.1 \\
\hline 1 & 100.0 & & & 1 & 0.1 \\
\hline 34 & 70.8 & 14 & 29.2 & 48 & 3.0 \\
\hline 26 & 68.4 & 12 & 31.6 & 38 & 2.4 \\
\hline 5 & 83.3 & 1 & 16.7 & 6 & 0.4 \\
\hline 2 & 100.0 & & & 2 & 0.1 \\
\hline \multirow[t]{2}{*}{1} & 100.0 & & & 1 & 0.1 \\
\hline & & 1 & 100.0 & 1 & 0.1 \\
\hline 41 & 91.1 & 4 & 8.9 & 45 & 2.8 \\
\hline 18 & 85.7 & 3 & 14.3 & 21 & 1.3 \\
\hline 12 & 92.3 & 1 & 7.7 & 13 & 0.8 \\
\hline 7 & 100.0 & & & 7 & 0.4 \\
\hline 4 & 100.0 & & & 4 & 0.3 \\
\hline 21 & 95.5 & 1 & 4.5 & 22 & 1.4 \\
\hline 19 & 95.0 & 1 & 5.0 & 20 & 1.3 \\
\hline 2 & 100.0 & & & 2 & 0.1 \\
\hline 19 & 90.5 & 2 & 9.5 & 21 & 1.3 \\
\hline 18 & 94.7 & 1 & 5.3 & 19 & 1.2 \\
\hline \multirow[t]{2}{*}{1} & 100.0 & & & 1 & 0.1 \\
\hline & & 1 & 100.0 & 1 & 0.1 \\
\hline 15 & 100.0 & & & 15 & 0.9 \\
\hline 13 & 100.0 & & & 13 & 0.8 \\
\hline 1 & 100.0 & & & 1 & 0.1 \\
\hline 1 & 100.0 & & & 1 & 0.1 \\
\hline 11 & 78.6 & 3 & 21.4 & 14 & 0.9 \\
\hline 8 & 88.9 & 1 & 11.1 & 9 & 0.6 \\
\hline 3 & 60.0 & 2 & 40.0 & 5 & 0.3 \\
\hline 8 & 61.5 & 5 & 38.5 & 13 & 0.8 \\
\hline 3 & 50.0 & 3 & 50.0 & 6 & 0.4 \\
\hline 2 & 100.0 & & & 2 & 0.1 \\
\hline 1 & 100.0 & & & 1 & 0.1 \\
\hline
\end{tabular}


Dye and pigmen

Non-food texturing agent

P Weapon/self-defense item

Q School and office supplies

Paper glue for school/office

Correction fluid

Ink (office material)

Felt-tip pen

R Air conditioning, cooling and heating products

Additive for heat transfer circuit

Refrigerant fluid

Heat transfer

S Reagents, laboratory dyes, developing products

T Cell/accumulator/battery electrolyte

U Fire prevention products (extinguisher)

V Printing and copying products

Printing ink (offset, etc.)

Printing and copying product, excluding ink (acid mordant, etc.)

Ink for printing cartridge (inkjet)

W Water treatment products (excluding pools)

Disinfectant for drinking water

$\mathrm{pH}$ adjuster/regulator (excluding pools)

\begin{tabular}{|c|c|c|c|c|c|}
\hline \multicolumn{2}{|c|}{ PSS 0/1 } & \multicolumn{2}{|c|}{ PSS $2 / 3$} & \multicolumn{2}{|l|}{ Total } \\
\hline 1 & 100.0 & & & 1 & 0.1 \\
\hline & & 1 & 100.0 & 1 & 0.1 \\
\hline 10 & 100.0 & & & 10 & 0.6 \\
\hline 9 & 100.0 & & & 9 & 0.6 \\
\hline 4 & 100.0 & & & 4 & 0.3 \\
\hline 2 & 100.0 & & & 2 & 0.1 \\
\hline 2 & 100.0 & & & 2 & 0.1 \\
\hline 1 & 100.0 & & & 1 & 0.1 \\
\hline 7 & 87.5 & 1 & 12.5 & 8 & 0.5 \\
\hline 3 & 75.0 & 1 & 25.0 & 4 & 0.3 \\
\hline 1 & 100.0 & & & 1 & 0.1 \\
\hline 2 & 100.0 & & & 2 & 0.1 \\
\hline 6 & 85.7 & 1 & 14.3 & 7 & 0.4 \\
\hline 4 & 100.0 & & & 4 & 0.3 \\
\hline 5 & 100.0 & & & 5 & 0.3 \\
\hline 4 & 80.0 & 1 & 20.0 & 5 & 0.3 \\
\hline 1 & 50.0 & 1 & 50.0 & 2 & 0.1 \\
\hline 2 & 100.0 & & & 2 & 0.1 \\
\hline 1 & 100.0 & & & 1 & 0.1 \\
\hline 2 & 50.0 & 2 & 50.0 & 4 & 0.3 \\
\hline 2 & 66.7 & 1 & 33.3 & 3 & 0.2 \\
\hline & & 1 & 100.0 & 1 & 0.1 \\
\hline & & 2 & 100.0 & 2 & 0.1 \\
\hline 1238 & 84.6 & 223 & 15.2 & 1464 & 92.5 \\
\hline
\end{tabular}

$\mathrm{X}$ Products for animals (e.g. litter) TOTAL

${ }^{a}$ Calculated based on the total numbers in the usage category; ${ }^{\mathrm{b}}$ Calculated based on the total numbers in the study. 